finally found that BMI and PD1 ${ }^{-}{ }{ }^{2} 28^{-}$Treg played important rules to developing lupus anxiety.

Conclusion: In this study, machine learning was applied to build models to select the most important T cell subset in SLE patients with anxiety. These findings suggested that $\mathrm{BMI}$ and imbalance of PD1 ${ }^{-} \mathrm{CD} 28^{-}$Treg containing effector memory Treg cells and effector Treg cells mostly played important roles in the development of SLE anxiety.

Disclosure of Interests: None declared

DOI: 10.1136/annrheumdis-2021-eular.3857

\section{AB0344 PREVALENCE AND RISK FACTORS FOR SEROSITIS IN PATIENTS WITH SYSTEMIC LUPUS ERYTHEMATOSUS: A CASE CONTROL STUDY}

L. Gimeno-Torres ${ }^{1}$, I. Carrión Barberà ${ }^{1}$, X. Duran ${ }^{2}$, T. C. Salman Monte ${ }^{1}$

${ }^{1}$ Hospital del Mar, Rheumatology, Barcelona, Spain; ${ }^{2} I M I M$, Statistics,

Barcelona, Spain

Background: Systemic lupus erythematosus (SLE) is an autoimmune multisystemic disease with a wide variety of clinical manifestations, being one of them serositis, which includes pericarditis, pleuritis and peritonitis [1]. Incidence of serositis ranges between $11-54 \%$ [2].

Objectives: To determine the prevalence of serositis in patients (pt) with SLE attended at the outpatient Lupus Unit and identify factors that could be used as predictors of this manifestation.

Methods: Retrospective case-control study. 297 medical records of SLE pt were reviewed: 28 pt were diagnosed with serositis (cases) and were age- and sexmatched with 2 controls with SLE without serositis. Differences between cases and controls were analyzed as well as factors associated with serositis.

Results: Patient's characteristics are described in Table 1. The prevalence of serositis in our cohort was $9.42 \%$. The difference between the prevalence of serositis in men and women was statistically higher in men, 30\% vs $7.9 \%$ ( $p=0.001, \mathrm{Cl} 95 \%: 1.7 \%-42.4 \%$ ). Serositis was diagnosed at an age of $41 \pm 14$ years (y) and in $40.7 \%$ it was the first symptom. Time from SLE diagnosis to serositis was $4 \pm 5.3$ y. 10 pt had recurrences: 6 had 2 , and 4 had 3 . Incidence of pericarditis and pleuritis was $78.6 \%$ and $82.1 \%$ respectively. 2 pt suffered from pericardial tamponade. Mean prednisone dose received during the serositis was $44.6 \pm 26.6 \mathrm{mg}$. At the moment of serositis $100 \%$ were ANA,$+ 85.7 \%$ antidsDNA+ $80 \%$ CrithidiaDNA+, 57.9\% antiRo60+, 52.6\% antiRo52+, $15.9 \%$ antiLa+, 47.4\% antiRNP+, $21.1 \%$ antiSm+, and $77.8 \%$ had low C3.

When looking for serositis-associated factors we only found association with antidsDNA measured by Crithidia $(p=0.016)$ and different measures of glucocorticosteroids (GC), having cases needed higher doses than controls (Table 1). Those with serositis had significantly received more mycophenolic acid $(p=0.021)$ and marginally, more belimumab $(p=0.056)$.

Table 1. Characteristics of cases and controls. *indicates mean \pm SD, Bold=statistically significant difference.

\begin{tabular}{|c|c|c|c|}
\hline VARIABLES & CASES (28) & CONTROLS (54) & $\mathrm{p}$-value \\
\hline Female & $22(33.3 \%)$ & $44(66.7 \%)$ & 0.775 \\
\hline Male & $6(37.5 \%)$ & $10(62.5 \%)$ & \\
\hline Caucasian & $20(32.8 \%)$ & $41(67.2 \%)$ & 0.693 \\
\hline Hispanic American & $7(38.9 \%)$ & $11(61.1 \%)$ & \\
\hline Others & $1(33.3 \%)$ & $2(66.6 \%)$ & \\
\hline Arthritis & $22(38.6 \%)$ & $35(61.4 \%)$ & 0.219 \\
\hline Leukopenia & $17(34.0 \%)$ & $33(66.0 \%)$ & 1.000 \\
\hline Lymphopenia & $25(33.8 \%)$ & $49(66.2 \%)$ & 1.000 \\
\hline Thrombocytopenia & $5(20.8 \%)$ & $19(79.2 \%)$ & 0.128 \\
\hline Nephritis & $8(50.0 \%)$ & $8(50.0 \%)$ & 0.152 \\
\hline Raynaud's phenomenon & $6(42.9 \%)$ & $8(57.1 \%)$ & 0.263 \\
\hline Haemolytic anaemia & $3(42.9 \%)$ & $4(57.1 \%)$ & 0.686 \\
\hline Antinuclear antibodies & $28(34.6 \%)$ & $53(65.4 \%)$ & 1.000 \\
\hline AntidsDNA & $23(37.7 \%)$ & $38(62.3 \%)$ & 0.295 \\
\hline AntiSm & $9(42.9 \%)$ & $12(57.1 \%)$ & 0.425 \\
\hline AntiRo52 & $10(41.7 \%)$ & $14(58.3 \%)$ & 0.444 \\
\hline AntiRo60 & $13(37.1 \%)$ & $22(62.9 \%)$ & 0.645 \\
\hline AntiRNP & $14(43.8 \%)$ & $18(56.3 \%)$ & 0.159 \\
\hline CrithidiaDNA & $19(47.5 \%)$ & $21(52.5 \%)$ & 0.016 \\
\hline Low C3 & $21(39.6 \%)$ & $32(60.4 \%)$ & 0.224 \\
\hline Low C4 & $13(38.2 \%)$ & $21(61.8 \%)$ & 0.637 \\
\hline Low $\mathrm{CH} 50$ & $13(39.4 \%)$ & $20(60.6 \%)$ & 0.480 \\
\hline SLICC* & $0.54( \pm 0.9)$ & $0.49( \pm 1.1)$ & 0.717 \\
\hline SLEDAI ${ }^{*}$ & $3.1( \pm 3.1)$ & $2.98( \pm 3.2)$ & 0.844 \\
\hline \multicolumn{4}{|l|}{ Corticosteroids } \\
\hline Ever & $27(38.6 \%)$ & $43(61.4 \%)$ & 0,051 \\
\hline Pulses ever & $9(60.0 \%)$ & $6(40.0 \%)$ & 0.033 \\
\hline \multicolumn{4}{|c|}{ Maximum prednisone dose ever: } \\
\hline$<10 \mathrm{mg}$ & $18(85.7 \%)$ & $3(14.3 \%)$ & 0.003 \\
\hline $10-29 \mathrm{mg}$ & $14(87.5 \%)$ & $2(12.5 \%)$ & \\
\hline $30-60 \mathrm{mg}$ & $11(45.8 \%)$ & $13(54.2 \%)$ & \\
\hline$>60 \mathrm{mg}$ & $8(47.1 \%)$ & $9(52.9 \%)$ & \\
\hline
\end{tabular}

Conclusion: The prevalence of serositis was $9.42 \%$. Serositis is significantly more frequent in SLE men than in women: almost $1 / 3$ will develop serositis, so we need greater awareness of serositis in SLE men.

CrithidiaDNA+ was identified as an associated factor of serositis. Furthermore, pt with serositis significantly received more pulses of GC and a higher maximum dose throughout the disease, which could imply a more aggressive form of SLE than in those without serositis. No correlation was found between serositis and any other characteristic.

REFERENCES:

[1] Hochberg MC. Updating the American College of Rheumatology revised criteria for the classification of systemic lupus erythematosus. Arthritis Rheum 1997;40:1725

[2] Ryu S, Fu W, Petri MA: Associates and predictors of pleurisy or pericarditis in SLE. Lupus. Science. 2017, 4(1):e000221.

Disclosure of Interests: None declared

DOI: 10.1136/annrheumdis-2021-eular.3932

\section{AB0345 THE PROBABLE PLAYERS IN SYSTEMIC LUPUS ERYTHEMATOSUS (SLE) AND TYPE 1 DIABETES MELLITUS (T1DM)}

N. Mohannad ${ }^{1}$, M. Moaaz ${ }^{2}$, R. Mohamed Shehata ${ }^{3} .{ }^{1}$ Alexandria University Hospitals, Faculty of Medicine, Alexandria University, Internal Medicine Department, Alexandria, Egypt; ${ }^{2}$ Medical Research Institute, Alexandria University, Immunology \& Allergy, Alexandria, Egypt; ${ }^{3}$ Molecular Biology Department, Faculty of Science, Alexandria University

Background: SLE is an autoimmune disease (AID) of unknown origin. Several factors can contribute to immune dysfunction in SLE.

Interleukin 9 (IL9) is a newly emerging T cell-derived factor preferentially expressed by CD4+T cells: T helper 9 (Th9)

IL9 targets different cell lineages, and can contribute to the development of allergic \& AIDs

Whether abnormal expression and secretion of IL9 are present in SLE patients (pts) still unidentified. It is also unclear whether IL9 exerts main proinflammatory or anti-inflammatory activities in SLE. T1DM is characterized by inflammation of the pancreatic islets of Langerhans. Insulitis progresses over time and $\beta$ cells become destroyed then clinical DM is established. T1DM is regarded as a T celldriven AID

Objectives: Evaluation of the expression of CD4+ IL9+ T cells \& the level of IL9 in SLE pts compared to both healthy subjects \& pts with another AID:T1DM.Also, to evaluate the correlation of these expressions with clinical features, laboratory parameters and SLE activity

Methods: The study included: Group I 25 SLE pts fulfilling SLICC classification criteria divided into 2 subgroups (gps) according to SLE disease activity index (SLEDAI) IA: 20 pts with mild to moderate activity $(<12)$ IB:5 pts with severe activity $(>12)$ recruited from rheumatology clinic or internal medicine ward (Rheumatology unit), Main University Hospital, Alexandria. Group II 15 healthy individuals as a first control gp. Group III 15 pts with T1DM fulfilling the American Diabetes Association criteria as a second control gp. All pts were subjected to history taking, clinical examination,laboratory investigations: CBC,LFT,KFT,ESR,CRP,ANA,Anti-dsDNA,Th9 cell expression detection by flowcytometry and serum IL9 by ELISA

Results: There was no statistical difference between all gps as regards age \& sex but a significant increased ESR in SLE compared to controls \& T1DM $p<$ $0.001 \mathrm{p}=0.001$

Th9 expression was highly increased in SLE pts, range $0.13-4.54 \%$ \& mean $\pm \mathrm{SD}=1.50 \pm 1.47 \%$ than both control gps. In healthy controls Th9 ranged between $0.0-1.29 \%$ with mean $0.37 \pm 0.52 \%$, while in T1DM pts ranged between 0.03

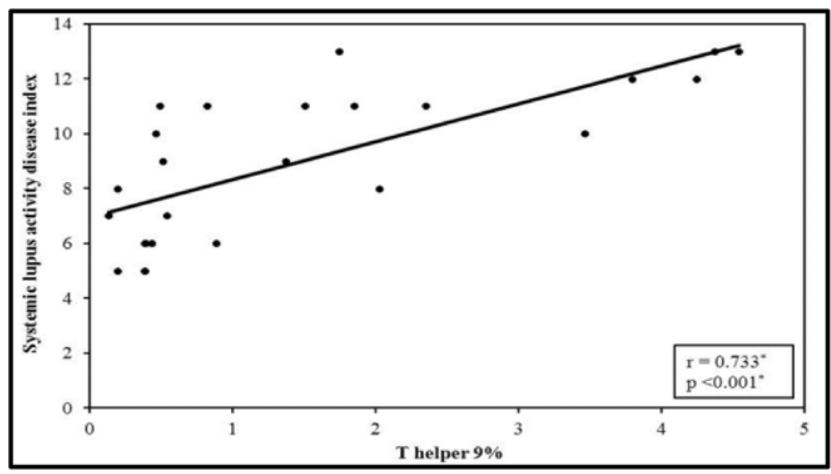

